\title{
Treatment for non-dysplastic Barrett's oesophagus: a well-informed, demanding patient
}

\author{
Luigi Dall'Olmo $\cdot$ Lorenzo Moja
}

Received: 13 August 2010/Accepted: 16 August 2010/Published online: 3 September 2010 (C) SIMI 2010

All full Cochrane reviews must include a Plain Language Summary which summarises the review in an easily understood style for consumers of healthcare [1]. The Plain Language Summary should be simple and brief without sacrificing important contents such as participants, intervention and outcomes. Plain Language Summaries are freely available on the internet, and so will often be read as standalone documents. Patients and consumers can educate themselves about their condition and treatment options. Based on a Plain Language Summary, a patient can ask questions and weigh alternatives before deciding. Then the patient can follow what seems to be the best advice, taking into account what is realistically available as treatment option. It is a doable task thanks to the Cochrane Collaboration and Internet. In the following Cochrane Corner, we present a fictional dialogue between a well-informed patient and a doctor who does not know everything.

Roger was one of my best mates at high school. We met again by chance in the cafeteria of the hospital where I work. It is always exciting to meet an old friend you haven't seen for a long time. We are both 51 years old now. It makes an impression to know that he is now a busy lawyer, a member of the General Court of the European Union. I updated him about my role: "I'm an internist, the deputy director of a hepatology unit". After a brief chat

\section{Dall'Olmo (四)}

I.O.V.-Istituto Oncologico Veneto-I.R.C.C.S,

Via Gattamelata, 64, 35128 Padua, Italy

e-mail: luigi.dallolmo@unipd.it

\section{Moja}

Italian Cochrane Centre, Mario Negri Institute

for Pharmacological Research, Via La Masa, 19,

20156 Milan, Italy

e-mail:moja@marionegri.it about life, wife and children, among other things, the delicate reason for his visit to the hospital surfaced. Roger started to tell me: "3 years ago, I was found to have a nondysplastic Barrett's oesophagus. Initially this diagnosis scared me, then I decided to fight the fear. I started to look on the internet to learn more about my condition. I would not define mine as a real disease though it can become a severe disease: oesophageal cancer" [2]. Roger was prepared. Briefly, he understood that there were basically three alternative therapies: medical (acid suppression), surgical (anti-reflux procedures) and endoscopic (mainly photodynamic therapy, argon plasma coagulation or radiofrequency ablation). He alternated technical jargon and everyday terms. The result was quite similar to that of many of my colleagues. I felt a bit uncomfortable listening, since this was not a familiar disease to me. I only had a vague recollection from university and some updates from medical journals. Of course, Roger was going to involve me in something that would require some advice as a friend and, worse, as a doctor.

"I've never suffered particular symptoms, only modest reflux from time to time," Roger says, "and my general practitioner told me the annual risk of oesophageal cancer was about $0.5 \%$ [3]." I wondered if Roger thoroughly understood this precise risk. Sometimes, numbers are not grasped properly. "After 1 year of follow-up, the Barrett's oesophagus becomes malignant in 1 out of 200 patients, giving a 1-year rate of $0.5 \%$ " I said. Roger continued: "I am under close surveillance, as recommended by many sources [4]. I worry about how I can avoid the risk of progression to cancer, since I've had different advice from three different doctors."

"The first one-my general practitioner-suggested I protect my oesophagus by taking high doses of proton pump inhibitors, and aspirin too." 
"The second expert is a famous surgeon who leads a team experienced in treating Barrett's oesophagus," said Roger. "He suggested an anti-reflux surgical operation, called Nissen fundoplication. He said this would protect me against the development of dysplasia [5]."

"The third doctor, an esteemed endoscopist told me that the latest strategy in this field is radiofrequency ablation, and it is the intervention of choice in cases of high-grade dysplasia. Even if the value of radiofrequency in non-dysplastic Barrett cases is uncertain, he thinks it should be offered to young patients like me, since it often has positive effects in less severe cases, like me. Furthermore, he said, it is safe."

"You are probably facing a situation in which the lack of one firm answer to your clinical problem means different doctors opt for different treatment opinions." Roger replied "All the doctors have given their advice. Now it is your turn."

"As we said, the risk of malignant progression is low, 1 in 200. Even so, it cannot be ignored. Every treatment should reduce this risk without affecting on your life style, for instance causing a problem of strictures, due to an imperfect healing."

"Drugs and anti-reflux surgery: it seems that there is not a clear benchmarking of these treatments [6]" Roger said.

"Both therapies are useful in symptom control [6], anyway. Proton pump inhibitors at a dose required to control symptoms are recommended in patients with reflux oesophagitis or Barrett's oesophagus [7]. I have heard about a trial, the AspECT trial. I remember it because to my knowledge it will be the largest phase III, randomised trial ever carried out for the medical treatment of Barrett, and the rationale has to be solid. This is a trial of aspirin and proton pump inhibitor chemoprevention in Barrett's patients. These combined drugs have anti-inflammatory and anti-acid effects. The AspECT trial findings will surely increase our knowledge, but they are not yet available [8]. The results will be fully transferable to your case. ${ }^{1}$

As for now, we know that medical therapies have little clinical effect on reversing Barrett's oesophagus [6] and there has been concern about the possible role of hypergastrinemia [9], a consequence of acid suppression, in favouring Barrett's progression or carcinoma development."

"A surgical approach would be attractive if it is definitive, meaning that your risk of malignant transformation becomes near to nil. Your doctor should be able to tell you what the studies show about the risks and benefits of surgery as opposed to doing nothing, focusing on people like you, considering your age, sex and medical history. Find

\footnotetext{
${ }^{1}$ AspECT trial is closed to recruitment. It has reached its target of 2,500 patients. Key Dates: Planned accrual completion, Feb 2009; First interim analysis, 2011; Final analysis and publication, 2016. http://www.octo-oxford.org.uk.
}

out what it entails and how long it will take for full recovery. Doctors have a tendency to downplay the discomfort patients experience after surgery. Be demanding of your doctor: ask for performance rates and surgery outcomes, if they do oesophageal function tests, and reflux monitoring."

"With the radiofrequency ablation, you would probably risk over-treating the disease if efficacy has only been demonstrated for dysplastic Barrett. I would rather rely on treatments that have been tested for the grade and severity of your disease, without extending the validity to a lower risk condition" I argued. "New in medicine is not always synonymous with better. Most of all, make sure your doctor communicates clearly to you, without medical jargon, so you understand exactly what you are facing in terms of possible adverse effects".

Roger summarised neatly: "It seems that there are no clear advantages for any one solution over the others."

"Sometimes the solution lies in remaining indecisive. That is particularly true when there are multiple options and uncertainties about the best treatment. Even a treatment that showed a net benefit in high-risk patients cannot be extended to you, since your risk is low. If it doesn't make a difference to your health outcome" I said, "take a few months, or even a few years, to see how your health and the risk evolve, and whether new evidence surfaces, to give a better perspective of the first-choice treatment in low-risk patients."

Before I said goodbye, I wanted to ask Roger how he kept up with all the medical information. He answered, "There are plenty of reputable sites with reliable information the average person can understand. I remember one by a specialised group of researchers and consumer representatives: the Cochrane Collaboration (http://www. cochrane.org)."

Conflict of interest None.

\section{References}

1. Schünemann HJ, Oxman AD, Higgins JPT et al. (2009) Presenting results and 'Summary of findings' tables, Chap. 11. In: Higgins JPT, Green S (eds.) Cochrane handbook for systematic reviews of interventions, version 502 (updated September 2009). The Cochrane Collaboration. http://www.cochrane-handbook.org

2. Vaira D, Gatta L, Ricci C, Castelli V, Fiorini G et al. (2010) Gastroesophageal reflux disease and Barrett's esophagus. Intern Emerg Med. doi:10.1007/s11739-010-0427-0

3. Sikkema M, de Jonge PJ, Steyerberg EW et al (2010) Risk of esophageal adenocarcinoma and mortality in patients with Barrett's esophagus: a systematic review and meta-analysis. Clin Gastroenterol Hepatol 8:235-244 (quiz e232)

4. Wang KK, Sampliner RE (2008) Updated guidelines 2008 for the diagnosis, surveillance and therapy of Barrett's esophagus. Am J Gastroenterol 103:788-797 
5. Parrilla P, Martinez de Haro LF, Ortiz A et al (2003) Long-term results of a randomized prospective study comparing medical and surgical treatment of Barrett's esophagus. Ann Surg 237:291-298

6. Rees JR, Lao-Sirieix P, Wong A et al (2010) Treatment for Barrett's oesophagus. Cochrane Database Syst Rev 1:CD004060

7. NICE (2005) Dyspepsia-management of dyspepsia in adults in primary care. National Institute for Clinical Excellence Clinical Guidance 2005, vol. CG17
8. AspECT: a phase III, randomised study of aspirin and esomeprazole chemoprevention in Barrett's metaplasia. 2004-003836-77. http://www.octo-oxford.org.uk

9. Harris JC, Clarke PA, Awan A et al (2004) An antiapoptotic role for gastrin and the gastrin/CCK-2 receptor in Barrett's esophagus. Cancer Res 64:1915-1919 